\title{
Epilepsy Comorbidity of Autism in Children
}

\section{Kun-Long Hung}

Department of Pediatrics, Cathay General Hospital, Taipei, Taiwan

Corresponding author: Kun-Long Hung, Department of Pediatrics, Cathay General Hospital, Taipei/School of medicine, Fu-Jen Catholic University, New Taipei, Taiwan Tel: 886-2-27082121; Fax: 886-2-27082423; E-mail: klhung@cgh.org.tw

Received date: July 28, 2016; Accepted date: July 29, 2016; Published date: July 31, 2016

Copyright: (c) 2016 Hung KL. This is an open-access article distributed under the terms of the Creative Commons Attribution License, which permits unrestricted use, distribution, and reproduction in any medium, provided the original author and source are credited.

\section{Editorial}

Autism Spectrum Disorder (ASD) is a group of developmental disorder in children characterized by social interaction difficulties, verbal/nonverbal communication disturbance and stereotyped behaviors. ASD can be found in most countries all over the world, while the prevalence differs among areas. The association between autism and epilepsy has been recognized for a long time, yet the basis of association is little understood [1]. One of the main reasons comes from the fact that various diagnostic subtypes exist in many reports of epilepsy with ASD [2].

The prevalence of epilepsy among all children is estimated as $2-3 \%$, compared to $10-30 \%$ in autism $[3,4]$. In a retrospective review of Electroencephalography (EEG) data and review of medical charts, up to $40 \%$ of children with pervasive developmental delay were diagnosed with epilepsy [5]. A meta-analysis of epilepsy in autism from 10-14 studies (1963-2006) found that $21.4 \%$ of individuals with an intellectual disability had epilepsy, while $8 \%$ of those without an intellectual disability had epilepsy [6]. Therefore, epilepsy in autism was associated with intellectual disability and the prevalence of epilepsy paralleled the intellectual disability. A similar report showed that autistic children without additional neurological disorders have a much lower (approximately 6\%) rate of epilepsy [7]. The risk for epilepsy in ASD was significantly higher for females from several studies $[1,6,8]$. A followed-up study for 150 childhood diagnosed ASD when they were 21 years of age found that $22 \%$ had epilepsy [1]. For the majority of participants, seizures first began after the age of 10 years. Epilepsy was significantly more common in those with lower language ability ( $45 \%$ vs. $25 \%$ as with epilepsy compared to those without epilepsy) [1]. Another study on patients with ASD and epilepsy was associated with potential gross and fine motor problems, incontinence, social impairments and behavior disorders [8]. Individuals with autism and additional neurological impairment, such as cerebral palsy are at a higher risk for seizures [9]. The earlier studies showed that type of language dysfunction was a risk factor for seizures, with the highest percentage of seizures occurring in children with the deficits in receptive language [10]. They hypothesized that the association of severe receptive language disorders with epilepsy and autism implicated temporal-lobe dysfunction [3].

Several population-based studies exploring the association of ASD \& epilepsy have been conducted. The study in Finland of 4705 ASD children from 1987-2005 confirmed the association of epilepsy and ASD, stronger in those with intellectual disabilities, esp. among females [11]. Another nationwide cohort study in Sweden showed individuals with epilepsy were at increased risk of ASD, with the highest in those epilepsy diagnosed in childhood [12]. The recent population-based cohort study in Taiwan demonstrated the bidirectional association between ASD and epilepsy [13]. The adjusted hazard ratio (HR) of epilepsy in ASD was 8.4 in ASD group compared with non-ASD group, and vice versa, the adjusted HR for ASD was 8.4 in epilepsy group compared with non-epilepsy group. They concluded that ASD and epilepsy shared common risk factors. One important issue is about the necessity of routine screening. A study to screen ASD in 236 children with epilepsy showed $15-82 \%$ positive screening results depending on various diagnostic tools. 15 individual (7.2\%) was finally diagnosed to be autism. High risk or symptomatic children with epilepsy warrant screening for ASD.

Recently the biological basis of ASD \& epilepsy has been speculated. Several biological pathways are commonly involved in both disease process including gene transcription regulation, cellular growth, synaptic channel function and maintenance of synaptic structure $[14,15]$. A mini-review on neuropathological mechanism of seizures in ASD postulated two findings shared by ASD \& epilepsy: Abnormalities in minicolumn architecture and GABA neurotransmission. Both ASD \& epilepsy are associated with the excitatory to inhibitory imbalance of the cortex, causing high prevalence of epilepsy in ASD and increased prevalence of ASD in individuals with epilepsy [16].

\section{References}

1. Bolton PF, Carcani-Rathwell I, Hutton J, Goode S, Howlin P, et al. (2011) Epilepsy in autism: features and correlates. Br J Psychiatry 198: 289-294.

2. Mannion A, Leader G (2013) Comorbidity in autism spectrum disorder: a literature review. Res Autism Spectr Disord 7: 1595-1616.

3. Tuchman RF, Rapin I (2002) Epilepsy in autism. Lancet Neurol 1: 352-357.

4. Mannion A, Leader G, Healy O (2013) An investigation of comorbid psychological disorders, sleep problems, gastrointestinal symptoms and epilepsy in children and adolescents with autism spectrum disorder. Res Autism Spectr Disord 7: 35-42.

5. Gabis L, Pomeroy J, Andriola MR (2005) Autism and epilepsy: cause, consequence, comorbidity, or coincidence? Epilepsy Behav 7: 652-656.

6. Amiet C, Gourfinkel-An I, Bouzamondo A, Tordjman S, Baulac M, et al. (2008) Epilepsy in autism is associated with intellectual disability and gender: evidence from a meta-analysis. Biol Psychiatry 64: 577-582.

7. Pavone P, Incorpora G, Fiumara A, Parano E, Trifiletti RR, et al. (2004) Epilepsy is not a prominent feature of primary autism. Neuropediatrics 35 : 207-210.

8. Turk J, Bax M, Williams C, Amin P, Eriksson M, et al. (2009) Autism spectrum disorder in children with and without epilepsy: impact on social functioning and communication. Acta Paediatr 98: 675-681.

9. Steffenburg S, Steffenburg U, Gillberg C (2003) Autism spectrum disorders in children with active epilepsy and learning disability: comorbidity, preand perinatal background, and seizure characteristics. Dev Med Child Neurol 45: 724-730.

10. Tuchman RF, Rapin I, Shinnar S (1991) Autistic and dysphasic children. II: Epilepsy. Pediatrics 88: 1219-1225.

11. Jokiranta E, Sourander A, Suominen A, Timonen-Soivio L, Brown AS, et al. (2014) Epilepsy among children and adolescents with autism spectrum disorders: population-based study. J Autism Dev Disord 44: 2547-2557. 
Citation: Hung KL (2016) Epilepsy Comorbidity of Autism in Children. Epilepsy J 2: e111. doi:10.4172/2472-0895.1000e111

Page 2 of 2

12. Sundelin HE, Larsson H, Lichtenstein P, Almqvist C, Hultman CM, et al (2016) Autism and epilepsy: a population-based nationwide cohort study. Neurology 87: 192-197.

13. Su CC, Chi MH, Lin SH, Yang YK (2016) Bidirectional association between autism spectrum disorder and epilepsy in child and adolescent patients: a population-based cohort study. Eur Child Adolesc Psychiatry.

14. Eom S, Fisher B, Dezort C, Berg A (2014) Routine developmental, autism, behavioral and psychological screening in epilepsy care settings. Dev Med Child Neurol 56: 1100-1105.
15. Lee BH, Smith T, Paciorkowski AR (2015) Autism spectrum disorder and epilepsy: disorders with a shared biology. Epilepsy Behav 47: 191-201.

16. Frye RE, Casanova MF, Fatemi SH, Folsom TD, Reutiman TJ, et al. (2016) Neuropathological mechanisms of seizures in autism spectrum disorder. Front Neurosci 10: 192. 